\title{
39.アジア地域における二酸化硫黄の大気拡散に関する研究
}

\section{STUDY ON ATMOSPHERIC DIFFUSION OF SULFUR OXIDES IN ASIA}

\author{
岡田修平*、藤原健史 $* *$ 、松岡 譲 $* * *$
}

Shuhei OKADA*, Takeshi FUJIWARA**, Yuzuru MATSUOKA***

\begin{abstract}
Sixty percents of people in the world live in Asian area, and their economic activities earn twenty four percents of the total GDP all over the world. As the population increases and the economic activities, emissions of sulfur oxides and nitrogen oxides from combustion are increasing and the emissions cause not only local pollution but also global environmental pollution.

It is important to calculate the concentration of sulfur oxides that is emitted from the stack of large point sources. In this paper, a software package was developed to calculate the diffusion of sulfur oxides which is emitted from Asian large point sources by using the Japanese air pollution model, and this package was applied to diffusion problems by large point sources China, Korea and India's. The result is displayed as figures with GIS and the diffusion in each country was discussed.
\end{abstract}

KEYWORDS; sulfur oxides, large point source, GIS, atmospheric diffusion

\section{1 はじめに}

アジア地域には、世界人口の 6 割が住み、その経済活動は世界の GDP 合計の $24 \%$ 程度を占 めている。これらの人口の増加と経済活動の活発化に伴い、エネルギー消費は急増し、硫黄酸 化物、窒素酸化物、二酸化炭素などの排出量の増加が顕著で、局地污染に加えて地球環境に大 きな影響を与え始めている。また、工業の急速な発展や自動車の著しい増加により、大都市部 や工場周辺で煤煙や硫黄酸化物による被害がではじめ、中国などの都市では硫黄酸化物の観測 值がWHOの基準をかなり上回る状況にある。発展途上国では経済の振興が環境対策よりも優 先されがちであるが、いくつかの国々では、わが国の公害対策が本格的に実施された 1960 年 代の経済力に達していて、煤塵や硫黄酸化物などの環境対策に本腰を入れて取り組み始めてい る。アジアの多く国々では、先進国が有する高度で高価な環境技術よりはむしろ、それぞれの 国状に適したものが求められている(江幡禎則, 1997)。

本研究では煤煙の環境対策が十分でないアジア地域を対象として、火力発電所や工場などの 大規模固定発生源から移流・拡散する二酸化硫黄の濃度を、プルーム、パフモデルを用いて算 出し、GIS を用いて大気污染状況を視覚的に表示することを目的とした。

\footnotetext{
*京都大学大学院工学研究科環境工学専攻修士課程 Master of Environmental Eng., Graduate School of Eng., Kyoto Univ. **京都大学大学院工学研究科環境工学専攻助教授 Assoc. Prof. of Environmental Eng., Graduate School of Eng., Kyoto Univ.
}

***京都大学大学院工学研究科環境工学専攻教授 Prof. of Environmental Eng., Graduate School of Eng., Kyoto Univ. 


\section{2 大気拡散プログラムパッケージの概要}

本研究では、アジア地域の火力発電所・工場などの大点煙源から排出される二酸化硫黄の濃 度計算を行うプログラムパッケージを開発した。計算フローを図 1 に示す。

このパッケージでは、排出源データと気象データを入力として、排出源周辺における二酸化 硫黄の地上濃度を算出することができる。計算範囲を点煙源を中心とした $1000 \mathrm{~km} \times 1000 \mathrm{~km} \sigma$ 範囲とし、緯度・経度ともに 30 秒間隔で格子点をとり、その地点で濃度を計算する。以上の 操作をすべての点煙源について繰り返し、格子点での濃度を足し合わせる。求めた二酸化硫黄 の地上濃度を GIS 用いて画像表示する。なお、計算の対象国を中国、韓国、インドとした。

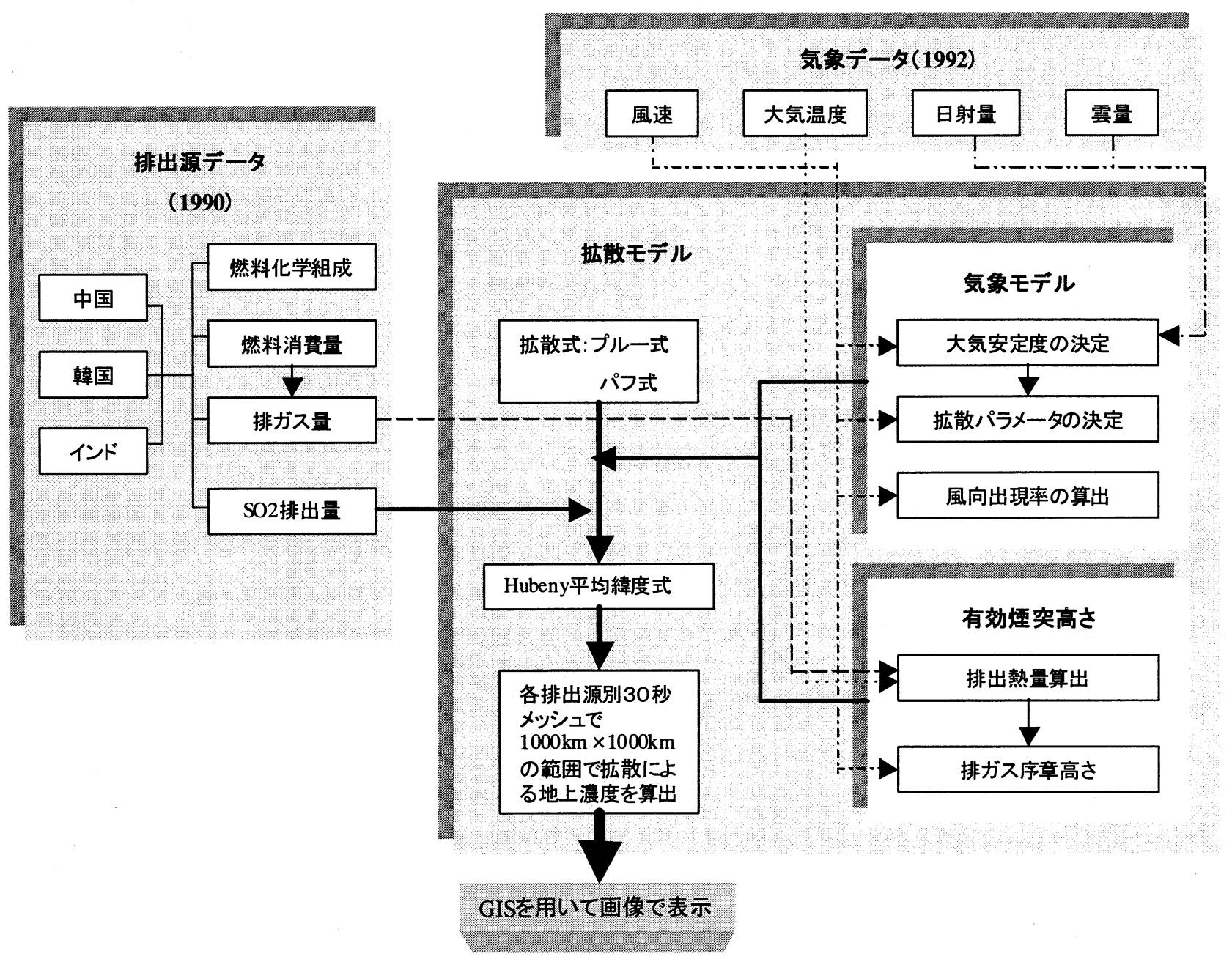

図1 大気拡散モデル概要図

3 大気拡散モデルの適用

\section{1 拡散式}

本研究では、環境庁の総量規制マニュアル(1995)に示される大気拡散モデルを用いて、二酸 化硫黄の地上濃度の拡散計算を行った。風速を $1.0 \mathrm{~m} / \mathrm{s}$ 以上の有風時、 $0.0 \mathrm{~m} / \mathrm{s}$ 以上 $0.5 \mathrm{~m} / \mathrm{s}$ 末満 の無風時、 $0.5 \mathrm{~m} / \mathrm{s}$ 以上 $1.0 \mathrm{~m} / \mathrm{s}$ 未満の弱風時に分類した。拡散式として、有風時のプルーム式と 無風時・弱風時のパフ式の 2 種類を用い、横方向一様分布式という形で用いた。この横方向一 様分布式とは、風向を 16 万位に区分 (22.5ำ間隔)し、区分内の風の出現率を用いて風向ごとに 濃度計算を行うものである。1 つの風向区分内では拡散濃度は風下距離に依存する(岡本眞一, 2001)。弱風時には総量規制モデルによる風向出現率の補正を行った。用いた風速データを 9 段階の風速階級に分類し、計算時間の短縮化を図った。拡散式の变数に用いられる有効煙突高 
さは、排ガス量から算出した排ガス熱量を、有風時は CONCAWE の式、無風時は Briggs の式 に与えることによって求めた(総量規制マニュアル 1975)。計算点の高さは、人の健康への影響 を考えて $1.5 \mathrm{~m}$ とした。

\section{2 気象モデル}

大気安定度は Pasquill の安定度階級分類表を用いた。本研究では大気安定度を以下のように して決定した。まず、任意の日時における地軸の傾きを算出し、その傾きから地球上の尽間の 範囲を算出した。求めた昼間の範囲から任意の経緯度における昼夜を判定し、昼間では気象デ ータの日射量と風速を、夜間では雲量と風速を用いて大気安定度を決定した。

プルーム式で用いる拡散パラメータを Pasquill-Gifford 安定度分類別に風下距離の関数とし て与えた。またパフ式で用いる拡散パラメータは総量規制マニュアルにあるように Tuner 図か ら求められる值を経験的に修正した值を用いた。

\section{3 排出源からの計算点の位置}

拡散式によって、任意の経緯度における計算点での地上濃度を計算した。計算範囲が広範囲 になると球面上での排出源から計算点までの距離や方位は平面上のそれとは異なる。本研究で は、Hubeny の平均緯度の式(高橋正義編, 1988)を用いて地球の球面上での距離、方位に修正し て拡散計算を行った。この式は、日本で準拠楕円体として採用されているベッセル楕円体につ いての子午線曲率半径や卯酉線曲率半径、赤道半径などの值を用いて、排出源と計算点の 2 点 の経緯度を与えることによって、これら 2 点間の距離・方位を求めることができる式である。

\section{4 入力テータ}

\section{(A) 気象テータ}

気象データには風速 $[\mathrm{m} / \mathrm{s}]$ 、大気温度 $[\mathrm{k}]$ 、日射量 $\left[\mathrm{W} / \mathrm{m}^{2}\right]$ 、 雲量 [0-1]のデータを用いた。これらのデータは European Centre for Medium-Range Weather Forecasts (ECMWF) のデ ータを用いた。データの詳細を表 1 に示す(ECMWF Data Services)。

\section{(B) 排出源テータ}

\section{(1) 二酸化硫黄排出量}

排出源データには人点煙源によるデータ、つまり Large Point Sourcc データ(以下「LPS デー 夕」と示す)を用いた。具体的には RAINS の David Streets らによる 1990 年の LPS データであ る。

拡散計算を行った中国、インド、韓国についての LPS データの概要を表 2 に示す。本研究で 用いた LPS の条件について以下に示す。

a) 排出源はすべて都市部に存在すると仮定した。

b) 排出量は年間を通して一定とした。

c) 対象となる排出源は以下の条件のどれかに当てはまる工場及び発電所とした。

(1) $500 \mathrm{MW}$ 以上の供給能力のある発電所

(2) $1,500 \mathrm{MW}$ 以上の熱投入量のある工場

(3) $\mathrm{SO}_{2}$ を年間 $20,000 t$ 以上排出する工場又は発電所

\begin{tabular}{|c|c|c|}
\hline \multicolumn{3}{|c|}{ 表 1 気象データ詳細 } \\
\hline \multirow{4}{*}{ 範囲 } & 北 & $\mathrm{N} 60.000^{\circ}$ \\
\hline & 西 & $\mathrm{E} 60.000^{\circ}$ \\
\hline & 南 & $\mathrm{S} 15.000^{\circ}$ \\
\hline & 東 & $\mathrm{E} 160.000^{\circ}$ \\
\hline \multicolumn{2}{|c|}{ メッシュ } & $0.5^{\circ} \times 0.5^{\circ}$ \\
\hline \multicolumn{2}{|c|}{ 開始期間 } & 1992.01.01.00 \\
\hline \multicolumn{2}{|c|}{ 終了期間 } & 1992.12.31.18 \\
\hline \multicolumn{2}{|c|}{ 時間間隔 } & 6時間ごと \\
\hline
\end{tabular}


表2 LPSの詳細

\begin{tabular}{ccccc}
\hline 国名 & LPS数 & 燃料成分 & 単位 & 対象年度 \\
\hline \hline 中国 & 83 & 重油、無煙炭(中間質) & $\mathrm{kt} / \mathrm{y}$ & 1990 \\
インド & 36 & 重油、無煙炭(高品質) & $\mathrm{kt} / \mathrm{y}$ & 1990 \\
韓国 & 3 & 重油、無煙炭(中間質) & $\mathrm{kt} / \mathrm{y}$ & 1990 \\
\hline
\end{tabular}

\section{(2) 排カス量}

排出源ごとの年間のエネルギー消費量 $[\mathrm{PJ} / \mathrm{y}]$ をもとにして排ガス量を計算した。まず、1990 年の LPS データに基づいた LPS 設備への熱投入量[MWh]にその設備の稼働率[-]をかけてエネ ルギー消費量を求め、各燃料成分の発熱量から燃料投入量 $[\mathrm{t} / \mathrm{y}]$ に換算した。次に、各燃料成分、 重油・無煙炭の化学組成のデータを用いて燃焼計算を行い排ガス量を体積単位で算出した。こ こで、重油、無煙炭の化学組成率は RAINS-ASIA のデータを利用した。最後に求めた排ガス量 と二酸化硫黄排出量から、排ガス中の二酸化硫黄の濃度を計算した。

中国、インド及び韓国の二酸化硫黄排出量と排ガス中の二酸化硫黄濃度をわが国の濃度と比 較したものを図 2 に示す。この図から、中国の二酸化硫黄排出量は多く、その排出量が多いほ ど二酸化硫黄濃度が高くなることがわかる。インドは二酸化硫黄濃度がほぼ一定で与えられて いる。わが国は脱硫装置の普及、良質の重油の使用など早くから二酸化硫黄対策を行ってきて おり、二酸化硫黄濃度は低い。

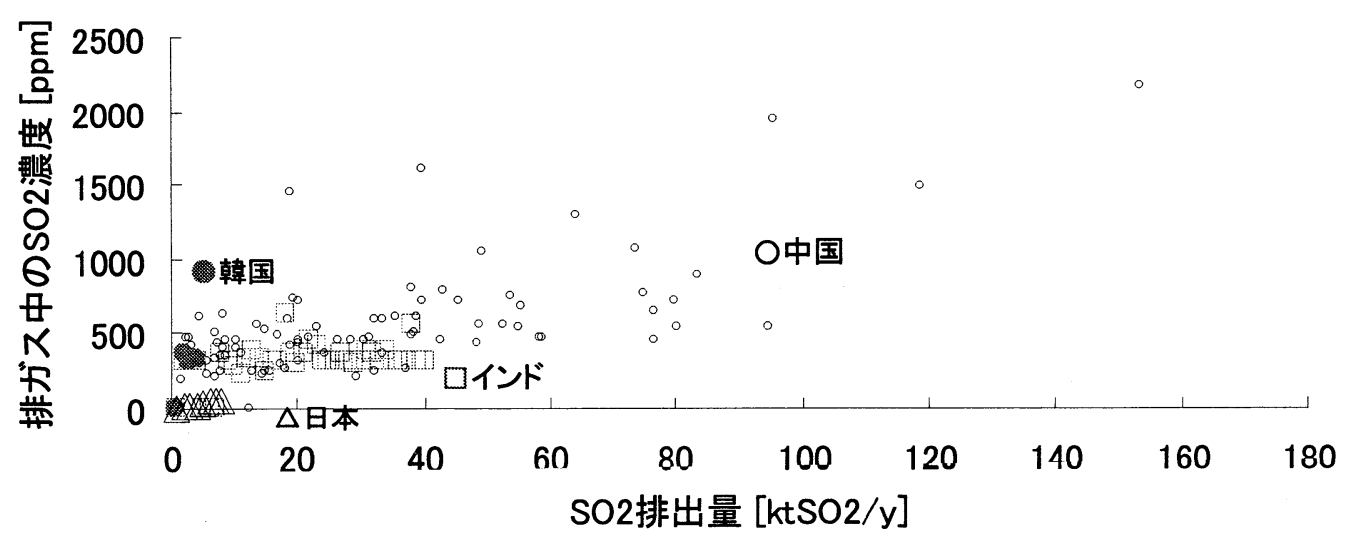

図2 対象国3ヶ国と日本との排ガス量及び濃度の比較

\section{5 計算結果及び考察}

中国、韓国、インドの 3 力国について、点煙源から拡散した二酸化硫黄の地上濃度をそれぞ れ求め、結果を図 3、4、5 に表示した。これらの図は拡散された二酸化硫黄の地上濃度を対数 表示し色分けしたものである。

中国では全体にわたって、二酸化硫黄の地上濃度は $10^{-3} \mathrm{ppm}$ 以上の值を示した。特に二酸化 硫黄の地上濃度が高かったところでは、タイハン山脈の周辺に位置するタートン炭田、ホワイ ナン炭田、太原(タイユワン)、鄭州(チョンチョウ)などで、その濃度は $0.01 \mathrm{ppm}$ のオーダーで あった。計算された地上濃度は最高で $0.04 \mathrm{ppm}$ を示し、日本の年平均二酸化硫黄濃度 $(0.01 \mathrm{ppm})$ の 4 倍の值であった。炭田地帯で地上濃度が高くなった理由は、石炭を利用した発電所や工場 がこの地域に集まっているためと考えられる。華北平原にも排出源が集中しており、 


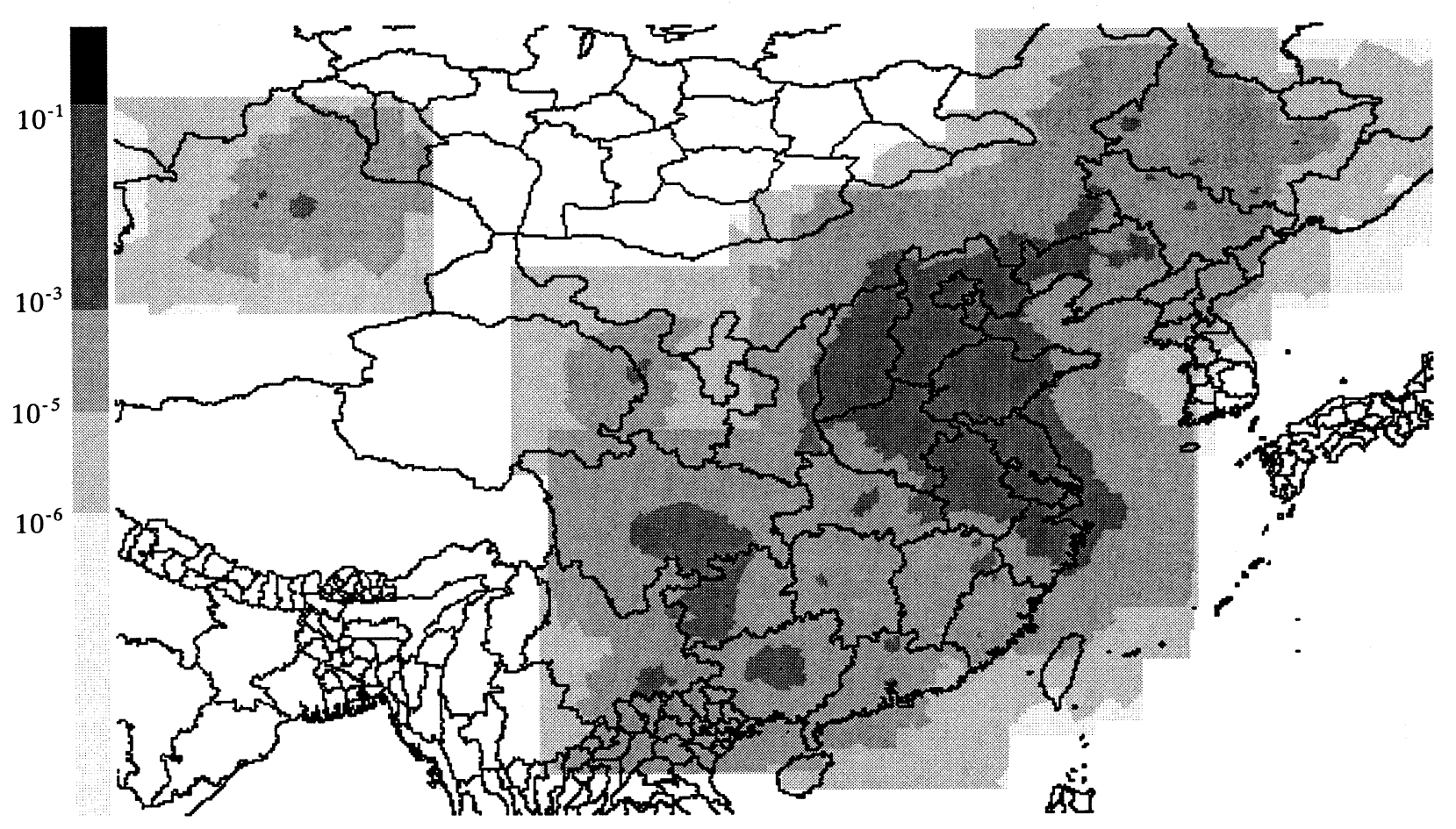

図3 中国全体における二酸化硫黄地上濃度分布

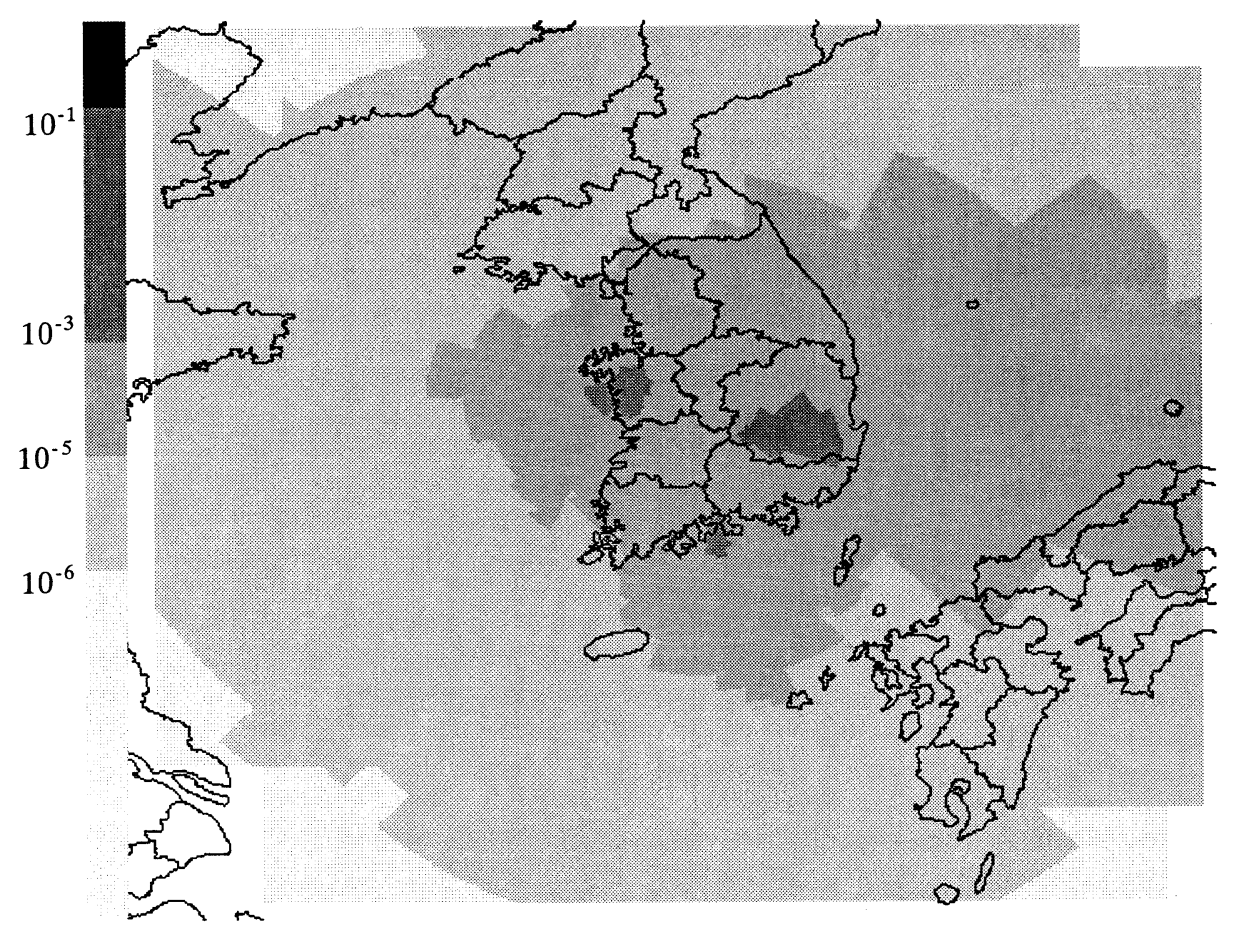

図4 韓国全体における二酸化硫黄地上濃度分布

そこでは東方向に拡散していることがわかった。また、工業都市重慶の周辺では独立して高い 濃度を示した。

韓国では全体にわたうて、二酸化硫黄の地上濃度は $10^{-4} \mathrm{ppm}$ 以上の值を示した。テーグ周辺 やインチョン、ソウルの大都市周辺で高い二酸化硫黄の濃度を示し、 $10^{-3} \mathrm{ppm}$ 以上の值を示し た。また韓国全体で、偏西風の影響とみられる強い東方向の拡散が見られた。 


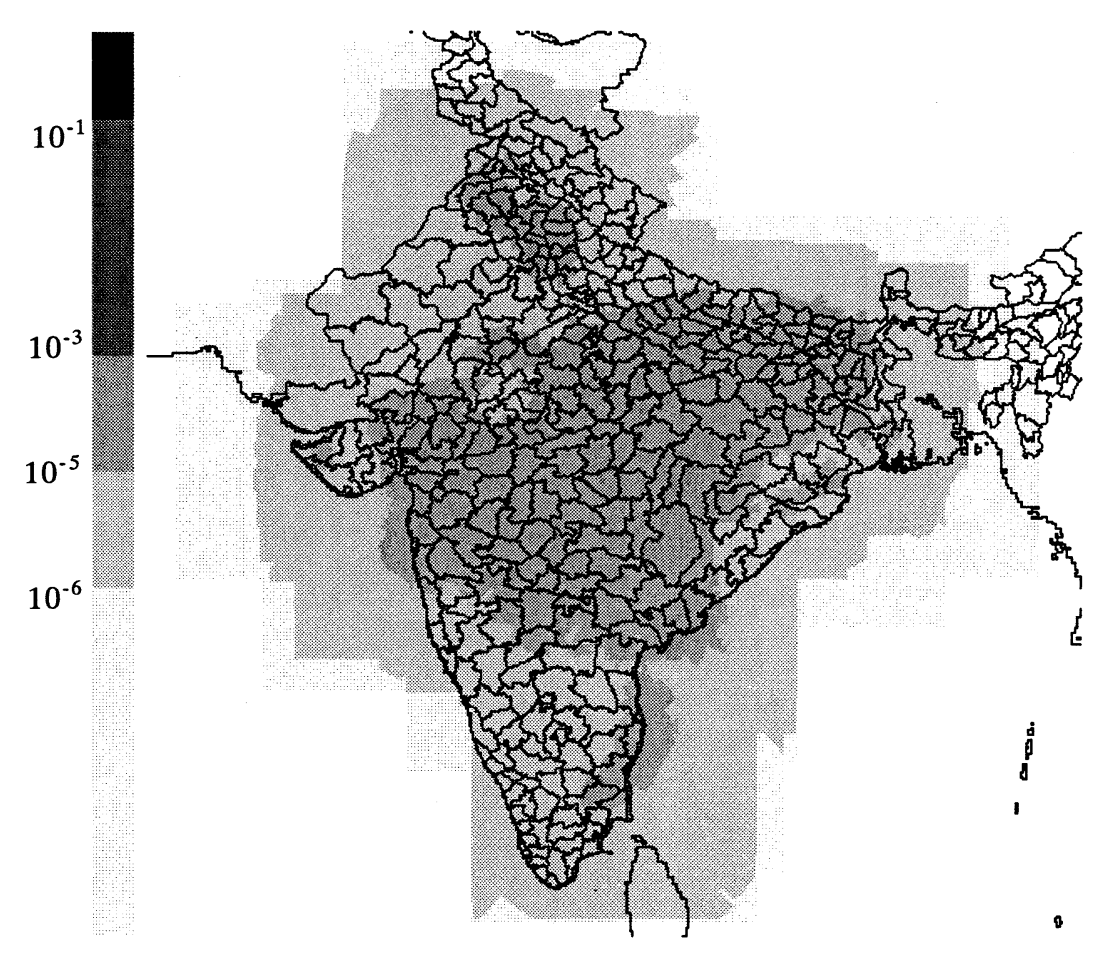

図 5 インド全体における二酸化硫黄地上濃度分布

インドでは全体にわたって、二酸化硫黄の地上濃度は $10^{-4} \mathrm{ppm}$ から $10^{-3} \mathrm{ppm}$ オーダーの值と なった。その中で高濃度を示した地域は、工業都市であるマドラス周辺、ラホールからデリー にかけての地域、インド北東部の炭田地帯、デカン高原周辺などであった。

以上の結果より、中国の二酸化硫黄の地上濃度は韓国とインドに比べて高い值であることが わかった。RAINS の韓国とインドの LPS データには排出量データが欠けているものがあり、 計算值は実際の濃度より低いと考えられる。なお、排出源には他に面煙源や長距離移動をする 二酸化硫黄があり、それらを全て加えた上で実測值と比較することが必要である。

\section{6 まとめ}

本研究で開発したモデルを用いて、LPS から排出された二酸化硫黄の地上濃度を算出し、そ の濃度の分布を画像で表示することができた。LPSごとに算出した地上濃度を重ね合わせるこ とによって、排出源が密集しているところでは地上濃度が高い值を示し、特に中国では、日本 での年平均二酸化硫黄濃度を超える地域も広範囲で存在することが視覚的にわかった。

\section{文 献}

岡本畺一(2001):大気環境予測講義 ぎょうせい.

江幡禎則 (1997):東アジア諸国のエネルギー消費と大気污染対策 科学技術政策研究所ホーム ページ http://www.nistep.go.jp/achiev/abs/jpn/mat051j/mat051aj.html.

環境庁大気保全局大気規制課(1975):総量規制マニュアル 公害研究対策センター.

高橋正義編:総観地理学講座 3 地図学 地図の利用法 朝倉書店(1988)

David Streets, Markus Amann, Neelo Bhatti, Janusz Cofala, Collin Green(1995):AN ASSESMENT MODEL FOR AIR POLLUTION IN ASIA Capter4.

ECMWF Data Services パンフレット: http://www.ecmwf.int/ . 